\title{
ENCONTRO COM CIBORGUES NO HOSPITAL: CARTOGRAFIAS DE UM CAMPO CIRÚRGICO
}

\author{
Tonantzin Ribeiro Gonçalves \\ Rosane Neves da Silva \\ Universidade Federal do Rio Grande do Sul
}

RESUMO: O presente trabalho é fruto da consultoria em psicologia do trabalho realizado com trabalhadores da unidade de bloco cirúrgico de um hospital geral em Porto Alegre. Pretendeu-se discutir a relação constitutiva entre trabalho e subjetividade no contexto da enfermagem cirúrgica, buscando mapear modos particulares de fazer, sentir, sofrer e subjetivar, além de descrever e problematizar a organização do trabalho e as relações desejantes entre trabalhadores e hospital. Por fim, debate-se atravessamentos da contemporaneidade na atividade cirúrgica, tais como, a ciborguização, a biotecnologia, a engenharia genética, o questionamento do "eu" e a reconstrução da noção de corpo.

PALAVRAS-CHAVE: subjetivação; trabalhadores cirúrgicos; ciborgues.

\section{MEETING WITH CYBORGS IN THE HOSPITAL: CARTOGRAPHIES OF A SURGICAL WARD}

ABSTRACT: The present work is the result of the consultancy in psychology related to a work accomplished with workers in a unit of a surgical ward at a General Hospital in the city of Porto Alegre. The work intended to discuss the constitutive relation between work and subjectivity in the context of the surgical nursing, looking for the outline of peculiar manners of doing, feeling, suffering and making subjective. Moreover, the article describes and problemizes the organization of the work and the desirable relationships among the workers and the hospital. Finally, it discusses contemporary issues which permeate the surgical activity, such as, robotization, biotechnology, genetic engineering, the questioning of "me" and the reconstruction of the body notion.

KEY-WORDS: subjectivity, surgical workers, cyborgs.

O surgimento do hospital tal como hoje o conhecemos, espaço onde se imbricam avançadas tecnologias médicas e digitais tem como marco da transformação de suas funções o final do século XVIII (PITTA, 1990). O hospital, em seus primórdios, período que compreende a pós-revolução industrial, servia como uma instituição-depósito de mendigos, pobres, vadios, doentes e loucos com uma função social de higiene e disciplina (FOUCAULT, 2002). Essa "nobre" tarefa de acolher os mais necessitados e levar os doentes a uma morte mais tranqüila estava muito alinhada com o ideal cristão de caridade (FOUCAULT, 1981). As marcas da união entre saúde pública e religião, perduram até os dias de hoje nos corredores hospitalares, apesar da transformação da cura em mercadoria de consumo tecnológico.

Pitta (1990) aponta outro aspecto interessante a respeito do hospital como instituição social. Segunda a autora, o hospital passa a servir como uma espécie de ferramenta de isolamento e esconderijo para a doença e para o morrer, afastando do cotidiano, e por que não, da concepção de normalidade, processos que ainda faziam parte do convívio social na Idade Média. Ainda conforme a autora, a partir do século XIX, o princípio da transformação social do hospi- tal e de seus objetivos, a partir da revolução indusrial, confunde-se "com uma dupla ordem de técnicas: as técnicas do poder disciplinar - disciplinando o coletivo dos corpos em desarranjo social; e as técnicas de cuidados médicos - introduzindo seus ritos e saberes instrumentalizados pela Clínica enquanto tecnologia individual" (p.43). Assim, já no século XIX, a preocupação com a saúde coletiva parece surgir como uma primeira tentativa de controle sobre o corpo - sede da força de produção e trabalho - e não mais somente intentando a exclusão social dos indigentes e vadios.

No entanto, o hospital para além de regular somente seus pacientes e assear o cotidiano de toda a doença e sofrimento, exerce forte influência sobre seu contingente de trabalhadores, operando nestes um modo particular de lidar com seu objeto de trabalho. Hoje em dia os avanços tecnológicos na área informacional e dos equipamentos de análises biológicas, químicas e de imagens inserem, no âmbito dos processos de trabalho no hospital, a precisão, a automatização, o aumento da velocidade e também a diminuição do número de trabalhadores necessários para a realização das mesmas atividades. O trabalhador tornou-se dispensável em função da perda de um saber que o qualificava, ao mesmo tempo em que 
lhe é exigido cada vez mais atenção na regulação e manejo das tecnologias.

A partir deste panorama sobre a história dos hospitais, fica patente que os processos de subjetivação do trabalhador, neste contexto, são atravessados, de maneira cortante por noções histórica e socialmente contextualizadas de saúde, doença e morte. Os tensionamentos produzidos entre essas categorias de análise, e outras, trazidas pela contemporaneidade e pelas novas tecnologias, engendram formas de trabalhar e subjetivar no âmbito das relações de trabalho e dos modos de viver no hospital (GUATARI, 1997). E, é nesse cenário que se inserem a particularidade do trabalho em bloco cirúrgico, campo onde se imbricam de maneira bastante explícita as relações dos trabalhadores com as novas tecnologias e as exigências daí advindas. O presente trabalho tem como objetivo relatar experiências e reflexões realizadas a partir de atividades implementadas pela psicologia do trabalho junto a um grupo de trabalhadores de enfermagem em centro cirúrgico ${ }^{1}$. A afecção causada pela vivência com o trabalho e com os trabalhadores deste tipo de unidade e pelas excursões observatórias ao local, serviram como motivadores iniciais, para as reflexões aqui apresentadas. As visitas exploratórias à unidade cirúrgica atuaram, em certa medida, como dispositivos desterritorializantes. Expurgados da moldura protegida dos departamentos e serviços de um hospital, lugar tradicional de intervenção da psicologia, deparar-se cruamente com a vida pelos fios das máquinas, dos corpos expostos e entregues, convocanos a elaborar alguma âncora de entendimento que dê conta deste encontro.

A partir desta afecção provocadora, pretendeu-se discutir a tessitura da relação constitutiva entre trabalho e subjetividade no contexto de trabalhadores da enfermagem cirúrgica, buscando assim mapear modos de fazer, sentir, sofrer e subjetivar. Neste sentido, se demarca aqui o referencial da psicologia social, o qual diz respeito à indissociabilidade entre mundo e sujeitos e tomando-se como método, a cartografia (FONSECA, 2003; ROLNIK, 1987). Num primeiro movimento, intenta-se situar o leitor quanto ao objeto de pesquisa, oferecendo algumas imagens deste nicho e conduzindo-o também a experimentar certas afecções. Num segundo momento, se desliza para a temática central a qual diz respeito aos modos de subjetivar e trabalhar em unidade cirúrgica quando se procura descrever e problematizar a organização de trabalho e as relações desejantes entre trabalhadores e hospital. A seguir, discute-se alguns atravessamentos instituintes da contemporaneidade os quais parecem incidir diretamente sobre a atividade laboral em cirurgias, como, por exemplo, a ciborguização, a biotecnologia, a engenharia genéti- ca, o questionamento do "eu" e a conseqüente ressignificação e reconstrução da noção de corpo.

\section{CARTOGRAFANDO A ECOLOGIA VERDE: O AR DE ENCANTADO}

Buscando mapear o território do bloco cirúrgico, mundo pertencente aos seus trabalhadores e habitantes transitórios (pacientes), utiliza-se o método cartográfico. Com relação à constituição do objeto de pesquisa, Mairesse (2003) afirma que o conhecimento se produz na construção deste, processo que implica inevitavelmente em "engolir" o objeto fazendo-o tornar-se parte de nós mesmos e deixando-se atravessar e redesenhar por ele. Neste sentido, Regina Benevides de Barros (citada em MAIRESSE, 2003) define território como uma construção espacial subjetiva a qual permite a montagem e desmontagem de modos de ser dos sujeitos envolvidos. Rolnik (1989) também se utiliza da figura do antropófago para caracterizar o cartógrafo. Pensamos que a figura desse antropófago, no âmbito do bloco cirúrgico, precisou, além de engolir também se permitir digerir passivamente, isto é, deixar cortar sua carne, sangrar, remexer suas entranhas, implantar objetos estranhos. Deste modo, entender a paisagem, as belezas e os acidentes do centro cirúrgico, não significou explicar ou descobrir algo sobre este objeto de pesquisa - ou será do desejo? - mas mergulhar em meio às suas intensidades, estabelecendo conexões lingüísticas que permitam ao pesquisador integra-se em uma história e na constituição de territórios existenciais.

As vivências nesse contexto, repletas de temores e surpresas, iniciaram-se nos contatos com o grupo de técnicos e enfermeiros dessa unidade. O encontro com uma ecologia verde, o nicho dos poderosos cirurgiões, ao mesmo tempo execrados da medicina $^{2}$, exigiu, primeiramente, despir-se das próprias roupas, dos próprios saberes; ali se fala outra língua e se veste roupas e toucas verdes. O centro cirúrgico se alimenta de elementos do exterior, dos instrumentos esterelizados, dos pacientes que chegam, dos funcionários que se paramentam no vestiário. Comunica-se intensamente com seus diversos exteriores através dos expurgos, das televisões de evolução das cirurgias, as quais informam os parentes, do elevador interno que leva os "óbitos" ao morgue, do elevador do Arsenal de Instrumentos. Esse último setor supre os trabalhadores de cortantes e ligantes imprescindíveis para o arranjo de novas formas de agenciamentos biológicos de manutenção da vida.

Além destes espaços, as intervenções de outros setores, como a psicologia do trabalho e os recursos humanos na unidade, aparecem como dispositivos estrangeiros e, por vezes, experimentados como invasores ou inimigos. As perturbadoras e vertigino- 
sas discussões que emergiram a partir das visitas observatórias na consultoria em grupo ${ }^{3}$ foram combatidas como germes com ausências glaciais aos encontros. Os uniformes protegem o ambiente asséptico, das bactérias que carregamos e porque não dizer também de nossas diferenças. $\mathrm{O}$ ar que se respira também deve ser filtrado pelas máscaras, assim com o chão protegido de nossos calçados. Assim, são recepcionados os de "fora", de maneira brutalmente indiferente, metamorfoseando-se, e sendo neutralizados para não serem expulsos como invasores: silenciosamente, os forasteiros são devorados.

Neste ínterim, pode-se apresentar duas imagens, as quais são úteis para a visualização da paisagem afetiva do centro cirúrgico contemplado por este estudo. A primeira é de uma mulher levada em uma cadeira de rodas pelo corredor por dois residentes em direção a uma das salas cirúrgicas. Ela está visivelmente abalada pela situação que se aproxima. As lágrimas escorrem pelo seu rosto, transfigurado pelo medo. A residente é inevitavelmente perturbada pelos soluços, mas os rebate afirmando friamente: "Não precisa chorar". A mulher, inconformada, continua chorando. Uma anciã faz parte de uma segunda imagem a qual pode ser figurativa. Ela entra na sala deitada na maca e olha suplicante, com ar de pavor, para a técnica que a arrasta para a mesa cirúrgica sem dizer palavra. Os residentes despem seu peito velho e branco, sem pudor, dos panos verdes que the colocaram, colando-lhe os adesivos de monitoração cardíaca. A anciã olha suplicante para o também velho médico professor como que para abster-se da vergonha sentida no momento. Alheio, ele folheia distraidamente o prontuário da paciente. Por um instante, $o$ professor lembra da paciente, quando então colocalhe a máscara de oxigênio com anestésico: "-De onde tu és?"; “-De Encantado, Doutor"; "-Então, agora faz de conta que tu vais respirar um arzinho de Encantado".

\section{CAPTURAS SUBJETIVANTES E FUGAS DE SINGULARIZAÇÃO}

Erros? Quais erros? Eles não existem, não podem existir, reza a enfermeira, a lei do bloco cirúrgico. Para os trabalhadores da enfermagem, o limite está bem posto: o médico é dono do paciente e a unidade como um todo, por sua vez, parece ser dona das subjetivações, dos ritmos, das expressões, das máquinas, dos membros, barrigas e corações. O cirurgião comunica-se com sua instrumentadora por códigos de sinais, indicando instrumentais extremamente específicos, aparentemente indistinguíveis. Do paciente só se vê a região alvo da operação, o resto também está invisível por baixo dos lençóis verdes. Nada de palavras, o entendimento dá-se através de um ballet ma- nual de tesouras, fios, gases, bisturis e aparadores. A técnica de enfermagem deve poder prever o próximo movimento, o próximo corte, a quantidade do fluxo de sangue e as gases necessárias ao estancamento. Isolado no campo cirúrgico, o instrumentador não é de maneira nenhuma autônomo em seu trabalho, depende do circulante, das mãos infectadas e dos pés deste $^{4}$. A enfermeira passa pela sala supervisionando, organizando, mas o poder sobre o paciente e os movimentos dos técnicos e médicos permanece sendo o imprevisível andar do próprio procedimento, por vezes, ritualístico, por vezes, furação impetuoso. A vida pulsa em desatino, transborda.

Máquinas e humanos parecem se entrincheirar lado a lado no centro cirúrgico. O limite entre a natureza humana, tão "divinamente" constituída, e a natureza fabricada artificialmente está por um fio. Alta exigência de perfeição, de nunca esquecer de qualquer detalhe, não pode haver erros de movimentos, passos infalsos, não há tempo para treinar, aprender ou corrigir. As cirurgias que utilizam o recurso do vídeo, as quais são cada vez mais freqüentes e aplicáveis a diversas patologias, mostram, na televisão, os movimentos, incisões e aplicações de laser. As câmeras tornam-se os olhos da equipe cirúrgica a qual se guia agora pela realidade das imagens produzidas digitalmente e não mais pela realidade da carne do paciente. Na realização de transplantes de córnea e cirurgias oftálmicas em geral, o olho do cirurgião se acopla literalmente ao olho do microscópio, que, por sua vez, se acopla à lente da câmera e juntos operam verdadeiras proezas em diminutas dimensões. Quem assiste, pode sentir-se, por instantes em um cinema, pois as luzes da sala ficam apagadas e há somente um ponto de luz sobre o olho do paciente. A televisão exibe, para a equipe, os fantásticos e milimétricos movimentos do cirurgião e de sua instrumentadora que despeja, ritmicamente, ínfimas quantidades de líquido para lubrificar o olho, ao mesmo tempo em que alcança os instrumentais. A vida sendo remodelada vira mídia em tempo real! Mas isso ainda não basta ao ímpeto tecnológico dos humanos e à vontade de aproximar-se das máquinas. Recentemente, o Instituto Nacional de Prótese Neurológica dos Estados Unidos anunciou o desenvolvimento de um olho de vidro com uma minúscula câmera embutida, a qual captaria as imagens para chips eletrônicos implantados no córtex cerebral (NOVAES, 2003).

Os transplantes, outra atividade bastante comum, inserem no âmbito das cirurgias a avançada tecnologia da substituição de órgãos e implementam, ao mesmo tempo, a necessidade de novas técnicas de cuidado e aplicação de novas aparelhagens. Os trabalhadores de enfermagem precisam estar constantemente atualizando-se e refazendo treinamentos rela- 
cionados aos materiais, instrumentais e procedimentos trans-cirúrgicos. Foucault (1997) nos oferece uma perspectiva política sobre o assunto. Dentre outras tecnologias, o autor considera o transplante de órgãos um indício do intento biopolítico de causar a vida coletiva, utilizando-se da morte individual. Esta mentalidade para a manutenção da vida é bem presente na formação médica moderna, a qual assume, por vezes, uma visão maquínica e coisificada do corpo, ao mesmo tempo em que passa a entender as tecnologias em saúde como ferramentas mercadológicas (VAYSEE, 1995; NOVAES, 2003). Que o digam as mais avançadas técnicas de cirurgia plástica e escultura corporal.

Além destas tecnologias da vida e da morte acima explanadas, as quais atravessam a rede das relações na ecologia verde, outros analisadores mostraram-se importantes para o entendimento dos modos de trabalhar e constituir-se trabalhador no bloco cirúrgico. Dentre esses, pode-se destacar, primeiramente, a peculiar sensibilidade do tempo experimentado pelos sujeitos e as formas de apropriação do espaço de trabalho legitimadas, muitas vezes, pelas relações saber-poder. Expressões como "o tempo passa muito depressa aqui" denotam algo da exigência de uma aceleração intensa do ritmo de trabalho a qual provoca modos peculiares de experimentar a passagem do tempo. A atenção aos detalhes, beirando a obsessividade, a conferência interminável dos materiais e uma memória rápida também são outras exigências feitas ao trabalhador contribuindo para a aceleração dos movimentos e do pensamento. Na mesma medida em que se parcela as tarefas e se exige certa velocidade na sua execução, isto parece proporcionar ao trabalhador a possibilidade de um distanciamento afetivo do seu objeto de trabalho. Nesta direção, Silva (1998) propõe em relação aos trabalhadores de hospitais que "o fazer mais rápido é também fazer menos da coisa, deixar-se envolver menos por ela" (p.29). A fragmentação e a parcelização das tarefas, além da aceleração destas são instrumentos da organização do trabalho responsáveis pela supressão da dimensão intelectual deste, os quais, por sua vez, são elementos comuns ao modo de produção taylorista/fordista (ANTUNES, 1999).

Num lugar como um centro cirúrgico, esse tipo de relação com o objeto de trabalho acena vantagens tentadoras, pois enxergar o risco de vida que muitos procedimentos oferecem e olhar para o paciente indefeso e totalmente entregue às mãos da equipe, parece expor os trabalhadores a uma angústia diária insuportável. Muitas vezes, aprender a lidar rápida e friamente com os corpos, instrumentos e máquinas, é uma questão de sobrevivência em um hospital. Mesmo assim, freqüentemente, ouvem-se suspiros melancólicos pelos corredores, quando a realidade é tão bruta que não é possível negá-la: "Os doutourandos fizeram chacota com a paciente, ficavam chamando ela de gorda e 'banha', rindo e pegando no corpo dela. Foi horrível, achei que nunca mais ia conseguir voltar (ao trabalho)".

De um modo geral, a arquitetura hospitalar também se encarrega de distribuir e dividir o espaço rigorosamente, favorecendo o controle disciplinar sobre seus habitantes e o mapeamento de subjetividades reguladas por códigos profissionais distintos (FOUCAULT, 2002). Assim, a disposição dos setores e das salas cirúrgicas, facilita a administração e o controle exercido, basicamente, pela posição funcional das enfermeiras. As salas cirúrgicas são constituídas por ante-salas e portas principais com janelas de vidro as quais dão para o corredor, de onde também fica bastante fácil a vigilância. A divisão das salas por especialidades também parece favorecer a organização e o controle do que ocorre no bloco cirúrgico, ao mesmo tempo em que, preserva/aprisiona identidades profissionais (SILVA, 1998). A demarcação de campos profissionais também se alia à delimitação de valores distintos a cada um deles. As diferentes especialidades ocupam salas específicas e competem pelo lugar mais alto e importante na corrida pela manutenção de vidas. Revela-se também uma espécie de "zoologização" de certos procedimentos cirúrgicos. O estranho e o novo cintilam diante de nossos olhos e se tornam, neste caso, motivo de grande curiosidade, estupefação e até de diversão, como no caso da cirurgia de troca de sexo, por exemplo. De certa maneira, o imperativo da vigilância, da observação, do exame e da classificação, perpetua-se nesta ilustração, denotando a clínica do olhar, fundante da ciência e, conseqüentemente, permeando a formação médica e das áreas de apoio como a enfermagem (FOUCAULT, 1994).

As "maravilhas" realizadas e profetizadas pela medicina e o esquadrinhamento, pretensiosamente absoluto sobre os corpos e suas anomalias demonstram o poder conferido, historicamente, a esta disciplina a qual nasceu confundida com a própria noção moderna de ciência (FOUCAULT, 1994). Em função disto, não é sem motivo o interesse das outras disciplinas em se aproximar e aliar-se ao saber médico. No âmbito da unidade cirúrgica, a qual foi objeto deste estudo, o vocabulário medicalizado utilizado pela enfermagem e a atitude servil e obediente dos técnicos de enfermagem para com os médicos podem demonstrar suas intenções de proximidade com este campo de saber. Talvez por isso, também seja tão difícil dirigir-se ao médico, lhe fazer esperar, lhe dizer não ou discordar de alguma prescrição ou impressão diagnóstica. 
No entanto, o que na verdade pode parecer, à primeira vista, simples submissão, revela algumas possibilidades de subversão. Neste sentido, podemos referir a idéia foucaultiana a respeito da bilateralidade dos fluxos de poder (FOUCAULT, 1995). No bloco cirúrgico, os vetores de resistência da equipe de enfermagem parecem estar intimamente relacionados à construção de pequenos nichos de saber altamente especializados e acoplados de forma similar aos diferentes âmbitos do saber médico. Desta forma, antes de implementar uma espécie de caça às bruxas à área médica, é preciso vislumbrar outras nuanças e permeabilidades nesse tecido de relações entre saberes e fazeres. Assim, os movimentos de mudança e alteração de qualquer técnica cirúrgica ou na aparelhagem das equipes médicas são sincronizados com movimentos de apropriação e pesquisa por parte dos técnicos e enfermeiros. As diferentes especializações médicas e as relações com cada equipe cirúrgica na rotina da unidade servem, neste contexto, como artifícios para a circunscrição de um saber próprio à equipe de enfermagem e de movimentos de singularização (GUATARI \& ROLNIK, 1997). Ao mesmo tempo, e, estrategicamente, mantém-se publicamente um discurso de uma generalidade funcional essencial e imperativa, se negando, através disto, as preferências ou habilidades específicas. Neste sentido, podemos lembrar que a reestruturação produtiva impõe a exigência de uma maior flexibilidade funcional, participação, qualificação, responsabilização individual, além das mudanças temporais e, até mesmo, espaciais, nas relações de trabalho provocadas pelas tecnologias digitais (ANTUNES, 1999; LAZZARATO \& NEGRI, 2001).

Mesmo diante do quadro sócio-econômico e político contemporâneo, Guatari e Rolnik (1999) apontam que as formas de resistir e criar não exigem grande sofisticação. O dispositivo da singularização permite, segundo estes autores, a criação de modos de organização do cotidiano a partir da experiência e do conviver e não a partir de uma cultura de massa. Neste caso, podemos pensar as alianças quase fraternas entre equipes cirúrgicas e técnicos de enfermagem altamente especializados como dispositivos de subversão e singularização com relação à atmosfera da ecologia verde, aparentemente, tão inebriante quanto dominadora. Sedimentam-se processos subterrâneos de especialização profissional, resultando em técnicos que se especializam em instrumentais bastante específicos e tornam-se essenciais e intercambiáveis em determinadas equipes. Aprender as "manhas" de cada cirurgião, as suas preferências e cada detalhe de sua forma de operar fazem parte de uma estratégia de sobrevivência e, principalmente, de recriação do próprio trabalho. Às vezes, torna-se interessante para o técnico aprender a operar com e não mais somente ter conhecimento geral do instrumental. Deste modo, se potencializa a construção de redes externas de trabalho autônomo, pois alguns cirurgiões contratam instrumentadoras particulares para realizar procedimentos eletivos. Constituem-se, desta forma, os chamados times cirúrgicos.

Na sala de preparo dos pacientes, por exemplo, os técnicos que mais se identificam com o paciente ainda acordado têm a possibilidade de produzir um espaço de tranqüilização e ambientação. Em relação a estes momentos pré-cirúrgicos, Sant'Anna (2001) faz um paralelo interessante entre a experiência da cirurgia e as viagens aéreas, pois em ambas o paciente fica como que em suspenso de sua própria vida, entregue a mãos alheias, sujeito a descontinuidades, à fragmentação das atividades e a sensações inusitadas. Deste modo, percebemos que o trabalhador da sala de preparo precisa de uma sensibilidade afinada sobre as expressões afetivas dos pacientes além de habilidades quase maternais para criar um clima que inspire a este viajante, confiança, conforto e segurança. Neste sentido, autores como Antonio Negri (2001) e Lazzaratto (2001) apontam para a vigência hegemônica do trabalho imaterial na força de produção social. O trabalho imaterial estaria ligado primordialmente, ao trabalho doméstico da mulher, o qual engendra primariamente a subjetividade capitalista. Assim, os trabalhadores atuais precisam saber reproduzir as relações de mercado, constituir seus consumidores, encarnar uma interface de decisões e escolhas autônomas (LAZZARATO \& NEGRI, 2001). Frente a este cenário, os técnicos de enfermagem do preparo precisam conhecer seus pacientes desde o primeiro momento, respeitar suas demandas particulares e elaborar um tipo de atendimento personalizado para cada um. Recentemente, a sala do preparo foi totalmente reestruturada, climatizada e decorada por reivindicação desses trabalhadores. O espaço destinado às crianças também recebeu decoração especial e a consultoria de terapeutas ocupacionais.

Outra peculiaridade marcante do trabalho em bloco cirúrgico parece ser a invisibilidade literal dos trabalhadores uns em relação aos outros. Seja pelo ritmo e característica das atividades em cirurgia, as quais certamente exigem uma atenção redobrada, seja pelos modos de gestão e organização do trabalho, ser invisível parece estar associado a um modo particular e necessário de fazer profissional. Ser invisível, por vezes, significa não errar, já que o acerto nunca é apontado ou mesmo percebido. Com relação à invisibilidade, Foucault (2002) nos explica que os dispositivos disciplinares invertem a economia da visibilidade no exercício do poder, tornando este invisível 
enquanto expõe os assujeitados. Neste caso, estamos entendendo ser invisível como estar de acordo com a norma disciplinar, pois, sem seguir a norma o trabalhador estará exposto. Ao mesmo tempo, as forças contrárias aos estatutos impostos pela organização do trabalho, os fluxos desejantes, cooperativos e de autonomia também precisam ser invisibilizados, ou melhor dizendo, neutralizados. Aquilo que se enxerga está ligado àquilo que é pré-ditado.

Espreitados pela eminência do encontro com robôs cirurgiões, os trabalhadores da enfermagem também se esforçam por anular os limites ergonômicos de seus corpos e das condições de trabalho impostas pela realidade de um hospital universitário que sobrevive com os atrasados recursos do SUS. Os braços e tendões precisam ser consertáveis como máquinas e robôs. Nestas tentativas, são utilizadas diversas ferramentas farmacológicas para invisibilizar, para si mesmo e para o setor, a dor física e o sofrimento psíquico trazido pela ameaça da incapacidade. Os pacientes serão também invisíveis, opera-se um braço, um coração, um ovário? Às vezes, isso parece ser verdadeiro, o que implica que o parcelamento maciço do processo de trabalho da enfermagem produz também um parcelamento do paciente.

Por outro lado, as afecções provocadas pela natureza dos procedimentos e das práticas engendradas no centro cirúrgico podem constituir uma interessante problematização da trama das dinâmicas, vibrações e intensidades dos modos de relacionar-se (Rolnik, 1989). Podemos definir essas afecções como vertigens, algo de um medo provocado pelo encontro com os fantasmas monstruosos de nossas criações tecnológicas, como bem se pode ilustrar com a estória do Dr. Frankenstein, o qual afrontou a terminalidade e a natureza divina da criação, através de artifícios equilibristas de manutenção da vida (LE BRENTON, 1995). Deste modo, o bloco cirúrgico parece funcionar de forma radical e perfurante, impondo, constantemente, a necessidade de abrir, expor as entranhas, trazer à tona o escondido, o tumor, a veia entupida, a hérnia, para que sejam consertados. O processo de transplante de órgãos, tanto com doadores com morte cerebral como com doadores vivos, torna-se vertiginoso para os trabalhadores envolvidos. O pavor imemorial da contaminação da vida com a morte se personifica neste monstro cultural frankensteiniano, explicitando a instabilidade da identidade dos corpos e do próprio sujeito no contemporâneo (SILVA, 2000). Os relatos dos trabalhadores da enfermagem expressam sentimentos de desterritorialização e sofrimento diante da participação na retirada de órgãos: "Os médicos parecem uns urubus em cima da pessoa. Cada equipe tira um órgão e sai correndo. É horrível ver aqueles aparelhos sendo desligados e a pessoa morrendo. Estamos acostumados a participar de cirurgias que são para curar e na retirada de órgãos, a gente tem que acompanhar a pessoa para a morte. Depois ninguém quer 'fechar' a pessoa: é o serviço sujo".

Cortes e extirpações comunicacionais também fazem parte do clima tropical do centro cirúrgico, sujeito à trovoadas e chuvas torrenciais e repentinas. Algumas operações comunicacionais precisam ser realizadas para que se consiga estabelecer discursos e entendimentos no contexto das cirurgias. Num verdadeiro telefone sem fio, as informações e as mudanças que chegam tornam-se, da mesma forma com que se introduzem veias, válvulas, pinos de aço e órgãos estrangeiros em corpos de acolhimento, procedimentos delicados e prolongados até que possam ser totalmente digeridos. Os acontecimentos estão em total exposição: se alguém da equipe comete um erro, está sendo visto por pelo menos dez ou doze pessoas e, em pouco tempo, toda unidade saberá. As relações são cortantes, há um modo agressivo e radical de comunicar-se, e isso não inclui somente gritos e xingamentos, mas também olhares fuzilantes. As caricaturas de cirurgiões perseguidores e perversos também fazem parte de um cotidiano brutalizado. Sem dúvida, a solidão escorre de cada sala cirúrgica onde duplas de técnicos de enfermagem sentem-se abandonadas, entregues à vontade soberana das equipes médicas, assim como os próprios residentes, apartados de seus professores e enfermeiros, estes últimos encontrando-se, por sua vez, afogados em exigências administrativas e gerenciais cada vez mais extenuantes. No entanto, para tudo deve haver um remédio e sendo assim, nos espaços que restam preenchem-se com bolos, festas de aniversário, chás de panela, comemorações de efetivação e tantos outros motivos que se inventam e se reproduzem para dar conta deste isolamento.

\section{CORPOS E MÁQUINAS EM CAMPO CIRÚRGICO: O SURGIMENTO DOS CIBORGUES}

Até aqui vimos de que modo os trabalhadores da área cirúrgica parecem camuflar-se dentre as paisagens tecnológicas e afetivas que compõem o hospital e, especificamente, no centro cirúrgico. Este camuflar-se desvela a tentativa do trabalhadores de entrelaçar originalmente seus modos de existir à missão explícita da instituição, isto é, fazer viver. No entanto, poderíamos também aqui apontar um segundo tipo de análise relativa ao contexto dos trabalhadores em bloco cirúrgico e em hospitais em geral colocando-os em confronto com o cenário da reestruturação das relações produtivas. Trata-se de poder debater os atravessamentos políticos, tecnológicos e sociais que constituem intrinsecamente os sujeitos contemporâneos enquanto seres produtivos e se, ao invés de somente 
Gonçalves, T.R.; Silva, R.N. "Encontro com Ciborgues no hospítal: cartografias de um campo cirúrgico"

servirem para produzir massificação e domínio sobre os sujeitos, estes não podem ser vistos como dispositivos potencializadores da construção de narrativas subjetivas e singulares. Assim, mesmo introduzindo aqui a dimensão sociológica da análise, talvez pessimista, se pretende problematizar as possibilidades dos sujeitos enquanto agentes de singularização.

Assim, partindo da perspectiva da reestruturação produtiva, Antunes (1999) discute argumentos teóricos, filosóficos e fenomênicos que apóiam a centralidade do trabalho na sociedade contemporânea, mas indica uma profunda alteração da relação trabalho-capital. Dentre estas alterações, figuraria-se o fato do desemprego estrutural e do sucateamento das condições de trabalho e dos direitos do trabalhador estarem gerando outras formas de produtividade que não somente aquela imposta pela fórmula capitalista. Sob este aspecto, alguns trabalhadores do bloco cirúrgico nos mostram que suas teias produtivas estão estendidas também sobre o quintal do trabalho autônomo e terceirizado, no sentido de que podem estabelecer conexões de trabalho fora do espaço protegido de seu trabalho formalizado. Talvez se possa pensar que a instabilidade contemporânea do laço empregatício formal lance sobre todos uma certa necessidade de buscar garantias simultâneas em outras formas de trabalho, sejam elas, na maior parte das vezes, mantidas na clandestinidade pelo temor da demissão ou ousadamente assumidas como atividades liberais. Ao mesmo tempo, a inserção em massa da produção científica, através das máquinas inteligentes, também solidifica a reestruturação do processo produtivo, na medida em que, atua, em certa medida, a transferência das capacidades intelectuais humanas às máquinas, tornando o trabalho do homem mais imaterial e menos físico.

Considerando que o emprego sofre uma enorme crise e que o trabalho passa a, paralelamente, terceirizar-se, acoplar-se mais intimamente ao das máquinas e tornar-se mais intelectualizado, podemos dizer que o trabalho não produz mais somente riquezas materiais, se é que algum dia ele se restringiu a tais limites. Antes, o trabalho contemporâneo produz modos de vida, linguagens e sentires próprios, impulsionando a própria reprodução da força de trabalho (NEGRI, 2001). Nesse sentido, a noção de trabalho imaterial pode nos proporcionar algumas reflexões a respeito das relações que os trabalhadores do bloco cirúrgico tramam com a sua própria máquina humana, em sua sanguínea rotina, e com as outras máquinas. No encontro também repetitivo das relações imateriais que se colocam através das exigências de produtividade e das relações saber-poder, muita materialidade dolorida toma espaço garantido nas cabeças, nos braços e colunas com a ajuda das falhas ergonômicas das condições de trabalho. Os sujeitos são desafiados pelos limites de suas próprias máquinas no seu embate, por vezes, competitivo, com outras. O grande problema está em que o homem teima em aceitar seus limites, ao passo que as máquinas podem ser facilmente superadas por outras melhores e aceitam submissas a substituição, pelo menos por enquanto.

Neste sentido, para além do cenário imbricado da germinação das implacáveis dores físicas outras paisagens puderam ser alinhavadas junto aos trabalhadores em bloco cirúrgico. Por exemplo, a possibilidade do domínio tecnológico dos robôs cirurgiões neste meio, ao mesmo tempo em que amedronta com a perda de empregos, esconde também a chance de uma relação mais igualitária dos técnicos com os médicos, já que com isto, estes deixarão de ser os agentes principais das cirurgias e se alinharão ao lado da equipe de apoio a qual, por sua parte, pode tornar-se uma espécie de apoio de medicina e enfermagem mecatrônica. Esta ironia foi verbalizada por uma funcionária que confrontada com a responsabilidade pelo funcionamento das máquinas de controle cardiorespiratório e de RX disse: "Quero ver o que vai ser deles (médicos) quando tiverem os robôs, eles também vão ter que se desdobrar como nós ao redor destas máquinas".

Assim, percebe-se que a inserção das tecnologias digitais, dos computadores e a centralidade da mídia informacional parece ter ecos para além da cadeia produtiva, também na vida social como um todo e na própria vivência do corpo e de si como sujeito. Le Brenton (2003) nos alerta para a tendência atual da negação do corpo, o qual é dispensado na existência integral oferecida pelo ciberespaço. Segundo o autor, o corpo como fronteira identitária do sujeito sofre sérios riscos de dissolver-se frente à digitalização das interações, pois este está sendo progressivamente substituído pelo corpo eletrônico, o qual é vantajosamente imune à doenças, ao envelhecimento e a deficiência física. Neste sentido, podemos pensar que a engenharia genética, a inteligência artificial e os avanços da medicina em geral e da cirurgia plástica, especificamente, trazem consigo problemas da ordem do pensamento, da ética, da política e da cultura, já que põem em questão, filosofias e teorias sociais a respeito da noção de humanidade e de sua relação com suas próprias formas corporais. O corpo do homem, por sua vez, vem sendo progressivamente desvendado a partir do paradigma positivista e utilitário do renascimento assim como o desenvolvimento da mecânica aponta para o desenvolvimento do homem artificial e a reparação de seus defeitos. Neste caso, podemos nos perguntar como os trabalhadores do campo cirúrgico se defrontariam com essas inevi- 
táveis questões éticas e até mesmo filosóficas. Partindo da perspectiva destes, poderíamos colocar essa questão em outro nível. No bloco cirúrgico, a relação do homem com as máquinas, passa a ser dimensionada a partir da relação deste com a própria vida na sua busca ancestral pela sobrevivência. Ali corpos abertos esperam simplesmente por remendos que lhe permitam continuar produzindo-se. Instaura-se a ética da sobrevivência, a lei do viver acima de qualquer conseqüência. Por vezes, isto custa a perda de alguns valores a alguns sujeitos ou sensibilidades alteradas.

Diante deste cenário, Foucault (1997) nos oferece uma análise das formas de controle e poder da sexualidade na contemporaneidade as quais contribuem para forjar o que ele chama de biopolítica. Para ele a sociedade disciplinar foi atravessada pela possibilidade de um poder de causar a vida, invertendo a premissa da sociedade medieval a qual preconizava o poder de causar a morte e deixar viver. Foucault indica que vivemos um tempo em que a morte está sendo desvitalizada e, mesmo a ameaça da morte funciona como um pretexto para buscar desesperadamente a manutenção da vida, como no caso dos transplantes de órgãos. Segundo ele, o controle da natalidade/ mortalidade, a anticoncepção, a regulação da própria sexualidade e todo aparato da clínica médica são tecnologias de controle da vida e constituem esse biopoder.

A partir do encontro do artificial com o homem no engendramento da biopolítica, Haraway (2000), nos interpela com uma afirmação provocadora: o mundo contemporâneo está povoado por ciborgues e não mais antagonicamente por homens e máquinas. Haraway afirma que o conceito de biopolítica foucaultiano, acima citado, nada mais é do que a premonição da política-ciborgue, diante da relação cada vez mais íntima entre as pessoas e as tecnologias biológicas, genéticas, digitais, eletrônicas e mecânicas. O corpo está em constante mutação e sua hibridização com as máquinas torna-se evidente no contexto tecnológico dos trabalhadores de hospitais. O percurso aqui apresentado em relação à imposição de ritmos e cadências, à demarcação de espaços e tempos específicos e à aproximação perturbadora entre o trabalho das máquinas e o trabalho dos humanos nos leva a apontar um processo intenso de ciborguização do trabalho e dos próprios trabalhadores da equipe da enfermagem. Estes precisam assumir posturas, por vezes robotizadas, aprender movimentos mecanizados, regular as expressões do próprio corpo em prol da produção e ajustá-lo ao funcionamento das máquinas. Ao mesmo tempo, a experimentação afetiva, as vertigens e ímpetos devem ser afinados às exigências imperiosas do ciclo de pro- dução-consumo e às máquinas que o compõem. Devem ser afinados? Se por um lado os sujeitos parecem ser carregados sem reação por este fluxo reprodutivo capitalista, por outro, linhas de fuga são insistentemente desenhadas por estes sujeitos, apontando as bidirecionalidades das relações de poder.

Assim, tornar-se um trabalhador-ciborgue de enfermagem parece, em alguns casos, ser uma espécie de solução de compromisso entre a competição de futuro dolorido com as máquinas e a rejeição magoada às tecnologias. Alguns trabalhadores e pequenos grupos dentre eles parecem conseguir incorporar singularmente características e práticas técnicas e afetivas, as quais por sua vez, os possibilitam deslizar por outras interfaces através da sua relação com as máquinas e com o seu corpo tornado também máquina. Neste sentido, podemos relembrar a busca pelas especializações, por redes mais solidárias de trabalho e amizade, bem como as estratégias festivas e bemhumoradas de disfarce e subversão da competição e do isolamento. Os trabalhadores ciborgues dos campos cirúrgicos parecem estar incessantemente em busca do redesenhamento de fronteiras entre o artificial e o humano, entre a saúde e a doença, e por que não, entre a massificação e a singularização. Deste mesmo modo, Haraway (2000) propõe a possibilidade de inclinação subversiva dos ciborgues frente à premissa de um mundo com regras unívocas e rígidas. Estes seres ciborguianos habitantes de um mundo em parte ficção, em parte realidade, se encontrariam no cerne do questionamento atual sobre as fronteiras entre animal-humano, máquina-humano e físico/não-físico, tendo o poder de definir novas possibilidades e limites políticos, a partir de sua posição provocadora e irônica: "Nossos corpos são nossos eus; os corpos são mapas de poder e identidade. Os ciborgues não constituem exceção a isso (...). A máquina não é uma coisa a ser animada, idolatrada e dominada. A máquina coincide conosco, com nossos processos; ela é um aspecto de nossa corporificação. Podemos ser responsáveis pelas máquinas; elas não nos dominam ou nos ameaçam. Nós somos responsáveis pelas fronteiras; nós somos estas fronteiras" (p.105-106).

\section{NOTAS}

${ }^{1}$ Este trabalho foi fruto da experiência de estágio curricular da primeira autora no serviço de Psicologia do Trabalho de um hospital geral de Porto Alegre.

${ }^{2}$ Diz-se pelos corredores do hospital que os médicos que têm como função somente as cirurgias não são considerados médicos pelos próprios colegas, pois suas intervenções seriam puramente técnicas e pontuais. Coincidência ou não, Rouanet (2003) acrescenta que já no século XVIII os cirurgiões eram "assimilados aos barbeiros" da época, havendo uma separação ferrenha 
Gonçalves, T.R.; Silva, R.N. "Encontro com Ciborgues no hospítal: cartografias de um campo cirúrgico"

entre os médicos clínicos e os cirurgiões.

${ }^{3}$ A consultoria em grupo da psicologia do trabalho no bloco cirúrgico era realizada semanalmente, funcionando como um grupo aberto a todos os técnicos e enfermeiros da unidade. Esta consultoria teve a duração de três anos, tendo a participação dos diversos regimes de turno em diferentes momentos.

${ }^{4}$ As duas funções distintas que podem ser exercidas pelo técnico de enfermagem em sala cirúrgica dizem respeito à circulação e à instrumentação. $\mathrm{O}$ circulante está fora do campo cirúrgico esterelizado e é responsável pela substituição dos materiais, baixa dos instrumentais e por buscar medicamentos e aparelhagem extras. $\mathrm{O}$ instrumentador somente instrumenta a cirurgia.

\section{REFERÊNCIAS}

ANTUNES R. Os sentidos do trabalho: Ensaio sobre a afirmação e a negação do trabalho. São Paulo: Boitempo, 1999. 258p.

FONSECA, T. G. Gênero, Subjetividade e Trabalho. Petrópolis: Vozes, 2000. 213p.

FONSECA, T. G. Cidade Subjetiva. In: FONSECA T. G. et al. Cartografias e Devires. Porto Alegre: Editora da UFRGS, 2003. p. $253-258$.

FOUCAULT, M. O nascimento da clínica. Rio de Janeiro: Forense, 1994. 241p.

FOUCAULT, M. Microfísica do poder. Rio de Janeiro: Graal,1995. p.

FOUCAULT, M. A história da sexualidade. 14 ed. Rio de Janeiro: Editora Graal, 1997. 3v.

FOUCAULT, M. Vigiar e punir: História da violência nas Prisões. Petrópolis: Vozes, 2002. 288 p.

GUATARI, F; ROLNIK S. Micropolítica: Cartografias do desejo. Petrópolis: Vozes, 1999. 327p.

GUATARI, F. As três ecologias. Campinas: Papirus,1997. 56p.

HARAWAY, D. Manifesto Ciborgue: Ciência, tecnologia e feminismo-socialista no final do século XX. In: SILVA T. T. Antropologia do Ciborgue: As vertigens do pós-humano Belo Horizonte: Autêntica, 2000. p. 39 129.

LAZZARATO, M.; NEGRI, A. Trabalho imaterial: Forma de vida e produção de subjetividade. Rio de Janeiro: DP\&A, 2001. 108 p.
LE BRENTON, D. A Síndrome de Frankenstein. In: SANT'ANNA, D. Políticas do Corpo. São Paulo: Estação Liberdade,1995. p. 49-67.

LE BRENTON, D. Adeus ao corpo. In: NOVAES, A. $O$ homem-máquina: a ciência manipula o corpo. São Paulo: Companhia das Letras, 2003. p. 123-137.

MAIRESSE, D. Cartografia: Do método à arte de fazer pesquisa. In: FONSECA, T. G. et. al. Cartografias e Devires. Porto Alegre: Editora da UFRGS, 2003. p. 260 -275 .

NEGRI, A. Exílio: Seguido de valor e afeto. São Paulo: Iluminuras, 2001. 94p.

NOVAES, A. O homem-máquina: a ciência manipula o corpo. São Paulo: Companhia das Letras, 2003. 392p.

PITTA, A. Hospital: Dor e morte como ofício. São Paulo: Hucitec, 1990. 198p.

ROLNIK, S. Cartografia Sentimental: Transformações contemporâneas do desejo. São Paulo: Estação Liberdade, 1989. 304p.

ROUANET, S. P. O homem-máquina hoje. In: NOVAES, A. O homem-máquina: a ciência manipula o corpo São Paulo: Companhia das Letras, 2003. p. 37- 64.

SANT'ANNA, D. Corpos de Passagem: ensaios sobre a subjetividade contemporânea. São Paulo: Estação Liberdade, 2001. 127p.

SILVA, C. Trabalho e subjetividade no hospital geral. Psicologia Ciência e Profissão, Brasília, v.2, p. 26-33, 1998.

SILVA, T. Antropologia do Ciborgue: Vertigens do póshumano. Belo Horizonte: Autêntica, 2000. 142p.

VAYSSE, J. Coração estrangeiro em corpo de acolhimento. In: SANT'ANNA D. Políticas do Corpo. São Paulo: Estação Liberdade, 1995. 190p. 
Tonantzin Ribeiro Gonçalves é

Psicóloga formada pela UFRGS. O endereço eletrônico da autora é: tonanrib@yahoo.com.br.

Rosane Neves da Silva é professora do Instituto de Psicologia da UFRGS e orientadora no Programa de Pós-Graduação em Psicologia Social e Institucional da mesma Instituição. $O$ endereço eletrônico da autora é: roneves@cpovo.net

\section{Tonantzin Ribeiro Gonçalves e}

Rosane Neves da Silva

Encontro com ciborgues no hospital:

cartografias de um campo cirúrgico.

Recebido: 25/11/2004

$1^{\text {a }}$ revisão: 14/03/2005

Aceite final: 4/04/2005 